\title{
PARAMETRIC IDENTIFICATION OF INDUCTION MOTOR MATHEMATICAL MODEL WITH THE USE OF GENETIC ALGORITHM
}

\author{
K. Rutczynska-Wdowiak ${ }^{*}$, L. Zawarczynski*
}

\begin{abstract}
This paper presents the parametric identification of induction motor mathematical model with the use of genetic algorithm. The parameters of induction motor mathematical model were determined as a result of minimization of performance index. The work describes the formulation of parametric identification of induction motor mathematical model in the reference frame, matching the stator voltage vector and experimental investigations were performed for inverter-fed induction motor $(2,6 \mathrm{~kW})$.
\end{abstract}

Keywords: parametric identification, mathematical model, induction motor, genetic algorithm

\section{Introduction}

The mathematical model of an induction motor is a system of nonlinear differential equations, difficult for identification.

In literature (Pelczewski and Krynke, 1984) the model equations in two coordinate systems i.e. stationary and rotating in accordance with voltage, current or flux vector are presented.

In previous works showed (Stefanski, 1995 and Rutczynska-Wdowiak, 2017) that the use of classical static identification methods is limited because during the parametric identification process can take place the unstability of mathematical model solutions or the local minimum of performance index is determined instead of a global one. In such cases its proper to use genetic algorithms, because the genetic algorithm assures the larger probability of finding the global minimum of performance index than classical optimization method. In this paper the genetic algorithm was analyzed with regard to convergence, accuracy of the parametric identification process and the time of numerical calculations.

Parameters of the motor mathematical model were identified on the basis minimization of the meansquare error of angular velocity response and stator current signal, registered according to the assumptions: for the mains supply and for the step change of input synchronous frequency signal $\left(f_{s}=80 \mathrm{~Hz}\right)$.

Identification experiments was carried out for the start-up of the asynchronous motor with step change of angular stator frequency $\omega_{s}$ for mains supply $\left(\omega_{s}=314 \mathrm{rad} / \mathrm{s}, v=311 \mathrm{~V}\right)$ and with inverter-fed out $\left(\omega_{s}=502 \mathrm{rad} / \mathrm{s}\right)$ unloaded and loaded on the shaft by a hydraulic gear pump with throttling system.

\section{The induction motor mathematical model}

In this work the mathematical model of induction motor in the rotating $d$-q reference frame, in accordance with the stator voltage vector (1)-(2) was used (Pelczewski and Krynke, 1984).

Katarzyna Rutczynska-Wdowiak, PhD.: Department of Control \& Management Systems, Kielce University of Technology, Al. 1000-lecia PP. 7; 25 314, Kielce; PL, K.Rutczynska@tu.kielce.pl

** Lukasz Zawarczynski, M.Sc.: Department of Control \& Management Systems, Kielce University of Technology, Al. 1000lecia PP. 7; 25 314, Kielce; PL, L.Zawarczynski@tu.kielce.pl 


$$
\begin{aligned}
\frac{\mathrm{d}}{\mathrm{d} t} \phi_{d}(t)= & \phi_{q}(t) \omega_{s}(t)-R_{S} I_{d}(t)+v(t) \\
\frac{\mathrm{d}}{\mathrm{d} t} \phi_{q}(t)= & -\phi_{d}(t) \omega_{s}(t)-R_{S} I_{q}(t) \\
\frac{\mathrm{d}}{\mathrm{d} t} I_{d}(t)= & a_{1} \phi_{d}(t)+a_{3} \phi_{q}(t) \omega_{e}(t)-a_{2} I_{d}(t)+I_{q}(t) \omega_{s}(t)+ \\
& -I_{q}(t) \omega_{e}(t)+a_{3}(t) \\
\frac{\mathrm{d}}{\mathrm{d} t} I_{q}(t)= & -a_{3} \phi_{d}(t) \omega_{e}(t)+a_{1} \phi_{q}(t)-I_{d}(t) \omega_{s}(t)+ \\
& +I_{d}(t) \omega_{e}(t)-a_{2} I_{q}(t) \\
\frac{\mathrm{d}}{\mathrm{d} t} \omega_{e}(t)= & \frac{3 p^{2}}{2 J}\left(\phi_{d}(t) I_{q}(t)-\phi_{q}(t) I_{d}(t)\right)-\frac{p}{J} M_{o}(t),
\end{aligned}
$$

and

$$
a_{1}=\frac{R_{r}}{\sigma L_{S} L_{r}}, \quad a_{2}=\frac{R_{S}}{\sigma L_{S}}+\frac{R_{r}}{\sigma L_{T}}, \quad a_{3}=\frac{1}{\sigma L_{S}}, \quad \sigma=\frac{L_{S} L_{T}-L_{m}^{2}}{L_{S} L_{r}}
$$

where: $\phi_{d}, \phi_{q}$ - components of stator flux vector in the rotating reference frame, $I_{d}, I_{q}$ - components of stator current vector, $R_{s}, R_{r}$ - resistance of stator and rotor, $L_{s}, L_{r}$ - inductance of stator and rotor, $L_{m}$ - stator-rotor mutual inductance, $\omega_{e}$ - electrical angular velocity, $\omega_{s}-$ angular stator frequency, $J$ - inertia moment of motor and load, $p$ - number of pole pairs, $\boldsymbol{v}$ - modulus of stator voltage vector $\boldsymbol{v}_{s}$, $M_{o}$ - load torque (Rutczynska-Wdowiak, 2016, Stefanski, 1995, Stefanski and Zawarczynski, 2015).

\section{Formulation of parametric identification}

The motor mathematical model parameters were determined on the basis of minimization of performance index

$$
Q=\frac{1}{N}\left(K \sum_{i=1}^{N}(I(i)-\hat{I}(i))^{2}+\sum_{i=1}^{N}(\omega(i)-\hat{\omega}(i))^{2}\right)
$$

where: $K$ - an experimentally determined weight coefficient, $N$ - a number of measurements and " $\wedge$ " solution calculated from the mathematical model.

The parameters of used motor of power $2,6 \mathrm{~kW}$ and its substitute circuit according to the manufacturer are resp.: $R_{s}=1.52 \Omega, R_{r}=1 ., 37 \Omega, L_{s}=0.1822 \mathrm{H}, L_{r}=0.1828 \mathrm{H}, L_{m}=0.174 \mathrm{H}, J=0.0036 \mathrm{~kg} \cdot \mathrm{m}^{2}$.

The application block diagram of open-loop inverter control system with AC motor for the DSpace1103 card is shown in Fig. 1 . The RMS input voltage to the control system was set in form $v=2.875 * 80$ equal to $230 \mathrm{~V}$.

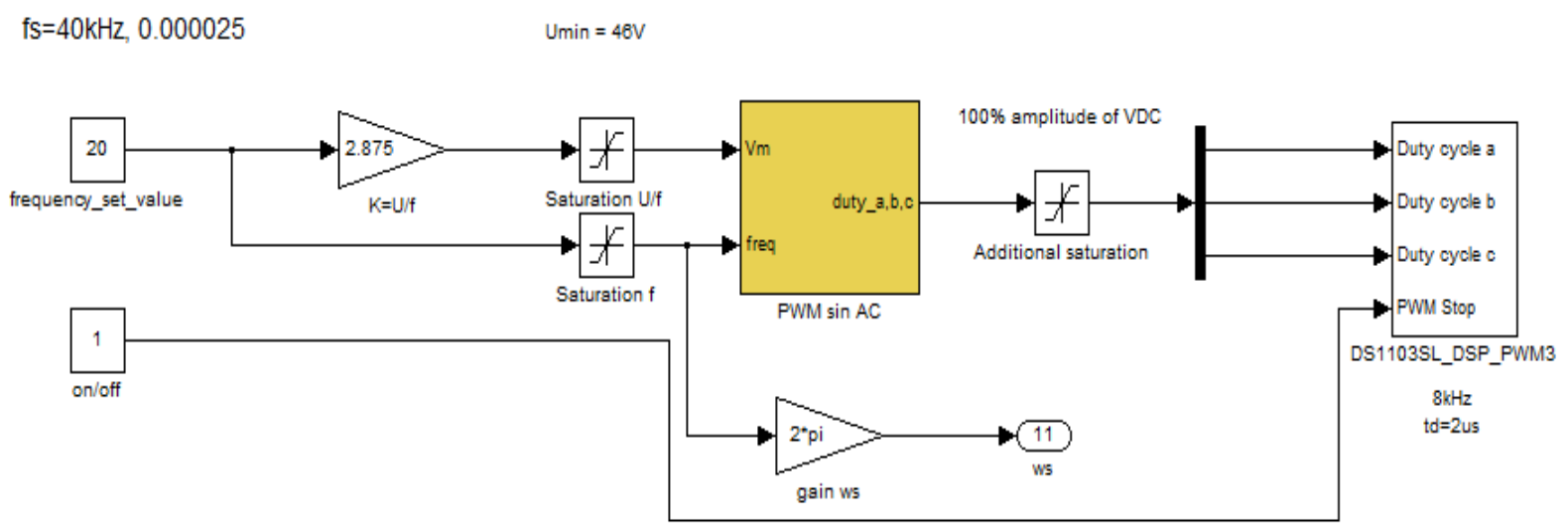

Fig. 1: The application schematic of control system. 
In the hydraulic system, the flow of working fluid was not throttled (no-load experiments), and the obtained load torque on the motor shaft resulted from the power absorbed by the hydraulic system, i.e. the flow generated by the pump and the installation resistance or throttle valve opening. The inverter system uses the $u / f=$ const control method. The full power characteristic has been set for the condition of the motor stator rated synchronous frequency $\left(f_{s}=80 \mathrm{~Hz}\right)$. Synchronous frequency $f_{s}$ is converted into a form of angular stator frequency $\omega_{s}$.

During the identification process the mathematical model parameters, such as: $a_{1}, a_{2}, a_{3}$ were determined. The moment of inertia $J$ was determined by the retardation test, and the stator resistance $R_{s}$ - by direct measurement $\left(R_{s}=1.85 \Omega, J=0.0036 \mathrm{~kg} \cdot \mathrm{m}^{2}, M_{o}=0\right)$. The voltage measurement was carried out in polyphase line-to-line system using LEM CV1000 Hall transducers, while the phase currents were carried out using LA55P transducers. In second case, parameters such as: $a_{1}, a_{2}, a_{3}$ and $J$ were obtained.

Because of stochastic character of genetic algorithm, every starting of identification procedure gives little different results and therefore in investigations the average result from 10 - experiments is given. The results of experimental identification of the motor mathematical model with the use of genetic algorithm are shown in Tab. 1.

Tab. 1: The results of experimental identification with the use of genetic algorithm.

\begin{tabular}{|c|c|c|c|c|c|c|c|}
\hline \multirow[t]{2}{*}{$\begin{array}{c}\text { Experiment } \\
\text { plan }\end{array}$} & \multicolumn{4}{|c|}{$\begin{array}{c}\text { Average values of identified } \\
\text { parameters }\end{array}$} & \multicolumn{2}{|c|}{$\begin{array}{l}\text { Average values of } \\
\text { multidimensional } \\
\text { correlation factors }\end{array}$} & \multirow{2}{*}{$\begin{array}{c}\text { Average } \\
\text { time } \\
\text { [s] }\end{array}$} \\
\hline & $a_{1}$ & $a_{2}$ & $a_{3}$ & $J$ & $\boldsymbol{R}_{\omega}$ & $R_{I}$ & \\
\hline $\begin{array}{l}\text { 3-phase main } \\
\text { supply }\end{array}$ & 3210.85 & 400.02 & 101.26 & - & 0.954 & 0.843 & 481 \\
\hline $\begin{aligned} t_{s} & =50 \mathrm{~Hz}, v \\
& =311 \mathrm{~V}\end{aligned}$ & 3213.01 & 401.43 & 100.22 & 0.0036 & 0.961 & 0.849 & 490 \\
\hline inverter -fed & 711.87 & 240.00 & 68.87 & - & 0.998 & 0.987 & 493 \\
\hline $\begin{array}{l}t_{s}=80 \mathrm{~Hz} \\
v / f_{S}=\mathrm{const}\end{array}$ & 713.41 & 243.78 & 67.02 & 0.0036 & 0.999 & 0.983 & 502 \\
\hline
\end{tabular}

Fig. 2 presents verification of the identification process, i.e. the comparison of the step responses of the drive with the AC motor and its mathematical model (1)-(2) for stimulation by a step change of input synchronous frequency $f_{s}=80 \mathrm{~Hz}$. It can be seen that a good convergence of induction motor time responses and its mathematical model was obtained.

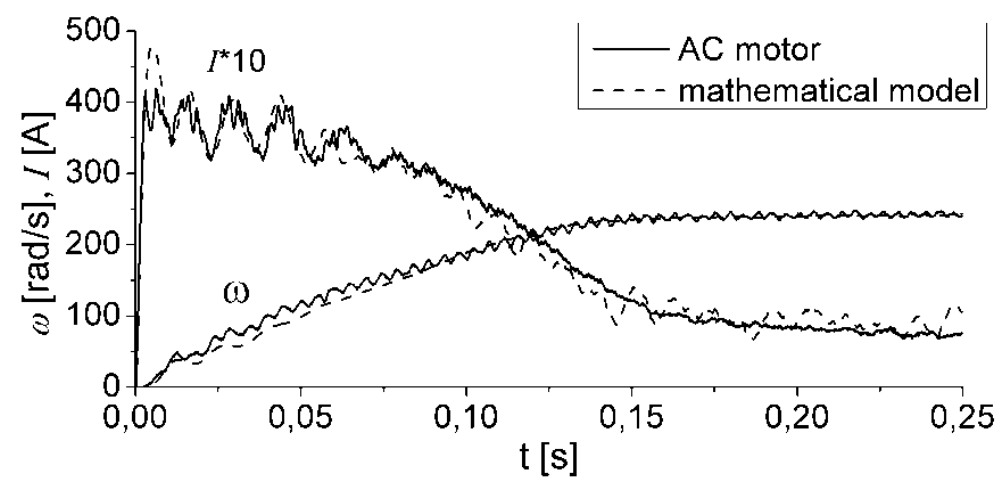

Fig. 2: The comparison of time responses of induction motor (solid line) and its mathematical model (dashed line) in identification process with the use of genetic algorithm.

\section{Conclusions}

This paper presents the parametric identification of induction motor mathematical model with the use of genetic algorithm. The investigations showed, that at present optimization method enable identification 
with good accuracy. The motor mathematical model parameters were determined correctly, but parametric identification is a time-consuming process.

Obtained identification results without load on the shaft are comparable with measurements at load. This also demonstrates the high stiffness of the power source in the form of the inverter system used. The experiment confirms that the static and dynamic properties of the drive for this type of excitation signal do not change significantly. The change in the number of determined mathematical model coefficients by additional determination of the moment of rotor inertia does not have a significant impact on the results of the analyzed process, i.e. on the values of correlation factors and the time of the process.

\section{References}

Alonge, F., D'Ippolito, F. and Raimondi, F.M. (1998) Parameter Identification of induction motors: Least Squares Vs. Genetic Algorithms. IFAC Motion Control, Grenoble, pp. 341-346.

Appel, M. and Grepl, R. (2017) Parameter estimation for engineers: a new tool for effective search for Simulink model parameters, in Engineering Mechanics 2017, Brno University of Technology, Brno, pp. 90-93.

Gorzalczany, M. B. and Rudzinski, F. (2017) Classification of Splice-Junction DNA Sequences Using Multiobjective Genetic-Fuzzy Optimization Techniques. Lecture Notes in Artificial Intelligence, 10245, pp. 638-648.

Hudy, W. and Jaracz, K. (2008) Identification of mathematical model induction motor's parameters using evolutionary algorithm and multiple criteria of quality, in Proc. 13th International Power Electronics and Motion Control Conference, pp. 912-915

Jancovic, M. and Zalman, M. (2006) Parameter identification of induction motor by genetic algorithm. AT\&P Journal, 2, pp. 90-96.

Michalewicz, Z. (2010) Genetic Algorithms + Data Structures = Evolution Programs. Springer-Verlag Berlin Heidelbderg GmbH.

Pelczewski, W. and M. Krynke, M. (1984) The method of state variables in the analysis of drive system dynamics. WNT (in Polish).

Rudzinski, F. (2016) A multi-objective genetic optimization of interpretability-oriented fuzzy rule-based classifiers. Applied Soft Computing, 38, pp. 118-133.

Rutczynska-Wdowiak, K. (2016) The parametric identification of induction motor mathematical model by genetic algorithm. The analysis of performance index. Electrical Review, 92, 4, pp. 202-204 (in Polish).

Rutczynska-Wdowiak, K. (2017) Replacement strategies of genetic algorithm in parametric identification of induction motor. 22nd International Conference on Methods and Models in Automation and Robotics, MMAR, IEEE, pp. 971-975.

Sadasivan, J. And Mammen, O. (2011) Genetic Algorithm based Parameter Identification of Three Phase Induction Motors. International Journal of Computer Applications, 31, 10.

Stefanski, T. (1995) Synthesis of adaptive torque control algorithms of inverter drive system for electrical vehicle with induction motor. Kielce University of Technology, 4, Kielce (in Polish).

Stefanski, T. and Zawarczynski, L. (2015) Problem of parametric identification of mathematical model of inverter traction drive with induction motor. Logistic, 4, pp. 5820-5829 (in Polish).

Tkachuk, R. Y., Glazyrin, A. S. and Polichshuk, V. I. (2012) Induction Motor Drive’s Parameters Identification Using Genetic Algorithms, in Proc. 7th International Forum on Strategic Technology (IFOST), pp. 1-4. 